\title{
Correlations of frontal resting-state EEG markers with MMSE scores in patients with Alzheimer's disease
}

\author{
Majid Torabinikjeh', Vahid Asayesh', Mahdi Dehghani', Aliakbar Kouchakzadeh²,3 ${ }^{2}$ Hanie Marhamati ${ }^{4}$ and \\ Shahriar Gharibzadeh ${ }^{2 *}$ (B)
}

\begin{abstract}
Background: A previous study suggests that resting-state EEG biomarkers measured at prefrontal region (Fp1, and Fp2) are moderately correlated with Mini-Mental State Examination (MMSE) scores of elderly people with Alzheimer's disease. In this study, our objective was to investigate whether resting-state EEG biomarkers recorded from frontal region are correlated with each MMSE sub-scores. 20 elderly patients diagnosed as Alzheimer's disease entered to the study. After completion of MMSE, subjects underwent EEG for 5 min with closed eyes condition. We measured median frequency, theta/alpha power ratio, and relative powers. To examine the relationship between these features and MMSE sub-scores first, Pearson correlation coefficients were computed for each feature and MMSE sub-scores. Then, $p$ values were computed for each correlation. Finally, a Bonferroni correction was done.
\end{abstract}

Results: Nine correlations have been found for markers recorded from F3, F7, and Fz. Alpha and beta relative powers were the markers which shows correlations. We found that MMSE overall, attention, and calculation scores are significantly correlated with beta relative powers recorded from F3, and Fz, and alpha relative power from F7. Orientation to time scores were correlated with F3, and Fz beta relative powers. The only correlation found for orientation to place was beta relative power of F3.

Conclusions: Our results indicate that there are correlations between frontal EEG markers and MMSE sub-scores of patients with Alzheimer's disease. The results show that alpha and beta relative powers are markers correlated with MMSE scores. It seems that if we want to develop predicting models for Alzheimer's disease, using data recorded from other frontal electrodes, especially what we have introduced should be considered.

Keywords: Dementia, Electroencephalography, Alzheimer's disease, Clinical neuroscience

\section{Introduction}

Alzheimer's disease (AD) is a growing problem that affects $35 \%$ of people over the age of 80 [1]. In 2015, AD was the sixth leading cause of death in the United States [2]. According to the criteria of National Institute of Neurological and Communicative Disorders and Stroke and the Alzheimer's Disease and Related Disorders

\footnotetext{
*Correspondence: s_gharibzade@sbu.ac.ir

${ }^{2}$ Cognitive Rehabilitation Clinic, Institute for Cognitive and Brain Sciences,

Shahid Beheshti University, Tehran, Iran

Full list of author information is available at the end of the article
}

Association (NINCDS-ADRDA), AD cannot be definitely diagnosed clinically, unless there is a histopathologic evidence. On the other hand, the NINCDS-ADRDA criteria proposes that cases with dementia established by clinical examination and documented by Mini-Mental State Examination (MMSE) can be assigned as "probable" AD patients [3]. MMSE is a short examination for assessment of cognitive abilities and is widely used for diagnosis of dementia in clinical setting. It includes examination of cognitive abilities that are diagnostic and clinically important for patients with AD (i.e., orientation to time and place, attention, calculation abilities, and recall) [4]. 
However, tries have been done to make the NINCDSADRDA criteria more reliable for researches using biomarkers of AD including Magnetic Resonance Imaging, Positron Emission Tomography, and cerebral fluid analyses [5]. Although resting-state electroencephalography (EEG) has not been yet considered as an approved method for initial evaluation of people with cognitive impairment, it is considered as a potential option for the diagnosis of dementia [6]. It becomes serious especially when we consider that EEG is relatively inexpensive [7].

Advancements in quantitative EEG (qEEG) for characterizing neuropsychiatric diseases have lead to further studies to clarify its diagnostic and prognostic uses in clinical and research setting $[8,9]$. Several studies on EEG biomarkers have been done that suggest various correlations with AD presentations. Prinz and Vitiello, in a classic research, proposed that lower alpha rhythm frequency was seen in $\mathrm{AD}$ patients compared to control subjects [10]. Prichep et al. found that an increase in theta absolute and relative powers is associated with mild cognitive deterioration, while an increase of powers in delta band is associated to more severe cases [11]. Their findings of absolute power were replicated by Chiaramonti et al., while they also suggested an increase in alpha and beta absolute powers recorded from more anterior regions [12]. Moretti et al. suggested that mild AD patients show lower alpha relative powers than normal subjects [13]. A review on the clinical perspective of EEG in dementia also suggested that EEG biomarkers can help to identify mild cognitive impairments from normal subjects [14].

Recently, several studies have been done on correlations between EEG biomarkers and MMSE scores of patients with dementia. Garn et al. suggest that MMSE scores of 79 probable AD patients are significantly associated with alpha relative power recorded in resting-state [15]. In 2019, Choi et al. found that resting-state EEG biomarkers measured at the prefrontal region (i.e., Fp1, and Fp2) are moderately correlated with MMSE scores. They suggest that finding correlations between EEG biomarkers and MMSE scores can be helpful to develop precise diagnostic and monitoring tools for AD [16]. A 2021 study by Doan et al. was done to identify whether prefrontal biomarkers are appropriate for screening dementia, using correlations between markers and MMSE scores [17].

It can be concluded, to develop tools for prediction of $\mathrm{AD}$, finding strong correlations between EEG biomarkers and each sub-scores of MMSE is worthy. It is suggested that the "orientation to time" score of MMSE is a strong predictor of subsequent cognitive decline [18]. It is also suggested that a decline in calculation abilities is one of the hallmark cognitive features of $\operatorname{AD}[19,20]$.
Recall assessment is also diagnostic in classification of patients with $\mathrm{AD}$, and can be used in detection of mild cognitive impairment $[21,22]$. In an overall view, it may be claimed that frontal cortex is dedicated for purposeful mental actions [23, 24], and because the MMSE consists of action-requiring examinations, it seems that the evaluation of frontal markers is an appropriate option to investigate correlations with MMSE scores of patients with $\mathrm{AD}$. In this study, our objective was to investigate whether EEG markers recorded from frontal region are correlated with MMSE scores of patients with AD. For this purpose, we examined data recorded from frontal region.

\section{Methods \\ Participants}

From November 2020 to February 2021, 20 elderly patients referred to the Asayesh Private Clinic diagnosed as AD entered to the study. All subjects were 55 years old or older. After examination, the attending psychiatrists put diagnosis on patients. The assessments and final diagnosis were done by the collaborating psychiatrist. The assessments were based on the current criteria for AD. All patients diagnosed both as dementia according the Diagnostic and Statistical Manual of Mental Disorders (DSM-V), and as probable AD according to the NINCDS-ADRDA criteria [3]. According to these criteria, a patient is diagnosed as probable $\mathrm{AD}$ if there are core clinical criteria for dementia, and also special characteristics for probable AD-e.g., insidious onset, clear-cut history of worsening of cognition by report or observation, etc. [25]. All participants were medication-free -i.e., not treated with any medication at least for 3 months. All participants had not any history of stroke and less than $5 \mathrm{~h}$ sleeping in the last night before referring to the clinic. All criteria were verified by asking patients' caregivers. Informed consents for entering to the study were taken by caregivers.

\section{MMSE completion}

After recording basic demographic information, the participants were examined with the MMSE. A Persian version of the MMSE used for cognitive examination [26]. This version consisted of eight sub-scores that in this study, we used four main sub-scores including Orientation to time (5 scores), Orientation to place (5 scores), Attention and Calculation (17 scores), Recall (3 scores), and altogether as an overall score (30 scores). The process of MMSE completion, including asking questions and recording answers, was conducted by nurses under the supervision of the attending psychiatrist. 


\section{EEG recordings}

After MMSE completion, Subjects underwent EEG for 5 min with closed eyes condition. The brain activities of subjects were recorded via EEG according to the International 10-20 system using Mitsar 19 channel system [27]. All the EEG electrode contact impedances were maintained below $5 \mathrm{k} \Omega$. To remove interferences from EEG, a high-pass filter with a cut-off frequency of $0.1 \mathrm{~Hz}$, a lowpass filter with a cut-off frequency of $50 \mathrm{~Hz}$, and a Notch filter with cut-off frequencies of 45 and $55 \mathrm{~Hz}$ were used. We used Infomax independent component analysis (Infomax ICA) decomposition to remove usual eye movement such as saccades or blinking [28]. Recordings were further cleaned with an automated $z$-score based method, using FASTER plugin [29]. After processing the EEG signal, various features were extracted from it.

\section{EEG markers and computation}

In this study, we measured Median Frequency of amplitude distribution of different frequency bands, Theta/ Alpha Power Ratio, and Relative Powers. These markers were reported as suitable classification biomarkers for $\mathrm{AD}$ [16]. Median that is calculated from median of amplitude distribution of times series of EEG signal at each frequency band including Delta $(1-4 \mathrm{~Hz})$, Theta (4-8 Hz), Alpha $(8-13 \mathrm{~Hz})$, Beta $(15-20 \mathrm{~Hz})$, High-beta $(20-30 \mathrm{~Hz})$.

Relative power has been used as a feature to classify the mild cognitive impairment and mild $\mathrm{AD}$ patients from age-matched controls $[30,31]$. The relative power of each given band/sum of power from 1 to $45 \mathrm{~Hz}$ was calculated by below:

$$
\mathrm{RP}\left(f_{1}, f_{2}\right)=\frac{P\left(f_{1}, f_{2}\right)}{P(1,45)} \times 100 \%
$$

Calculation of Relative Powers. $P(x)$ indicates the power, $\mathrm{RP}(x)$ indicates the relative power, and $f_{1}, f_{2}$ indicate the low and high frequency, respectively.

The ratios of power for slow frequency bands in frontal electrode was computed based on absolute powers of theta and alpha frequencies [32]. The recorded relative powers include delta, theta, alpha, beta, and gamma frequency bands. For EEG processing and metric computation, we used MATLAB software version 2019a.

\section{Statistical analysis}

For the purpose of this study, we analyzed EEG markers recorded from 7 electrodes consist of Fp1, Fp2, F3, F4, Fz, $\mathrm{F} 7$, and F8. EEG markers used in the analysis were 8 consist of delta median frequency, theta median frequency, alpha median frequency, Theta/Alpha power ratio, delta relative power, theta relative power, alpha relative power, and beta relative power. The analysis is conducted using the IBM SPSS software version 26.0.0.0. Pearson correlation coefficients were computed for each marker and MMSE overall score and sub-scores. $p$-values were computed for each correlations, then a Bonferroni correction was done by multiplying all $p$-values by 280 (7 electrodes $\times 8$ EEG markers $\times 5$ MMSE scores) and the level of significance set on $p<0.05$.

\section{Results}

\section{Demographic characteristics}

Among 20 individuals enrolled to the study, the majority was female $(70 \%)$. The mean age $( \pm S D)$ was $69.85( \pm 10.03)$. The mean MMSE overall score $( \pm S D)$ was $15.15( \pm 9.62)$ points that shows the majority of patients enrolled in the study had moderate-to-severe cognitive impairment. The pattern of approximately being half was repeated for each sub-scores (Table 1).

\section{Correlations between MMSE scores and EEG markers recorded from frontal region electrodes}

There was not any significant correlation between MMSE scores and each markers from Fp1, Fp2, F4, and F8. But, we found 9 significant correlations between MMSE scores and markers recorded from F7, F3, and Fz. Detailed results are presented in the following.

\section{F7 recordings}

The MMSE overall score was significantly and positively correlated with alpha relative power ratio $(p=0.024)$, that means with decrease in the MMSE overall score, the alpha relative power ratio decreases. The attention and calculation score was also positively correlated with alpha relative power ratio $(p=0.007)$. Any other significance has not been found for correlations between the MMSE scores and markers recorded from F7 (For details, see Table 2).

\section{F3 recordings}

The MMSE overall score was significantly and positively correlated with beta relative power ratio $(p=0.006)$. The orientation to time, orientation to place, and attention and calculation scores were also significantly and positively correlated with this feature with $p$-values equal to $0.011,0.035$, and 0.045 , respectively. Any other significance has not been found for correlations between other MMSE scores and markers recorded from F3 (For details, see Table 3).

\section{Fz recordings}

The MMSE overall score was also significantly and positively correlated with beta relative power ratio $(p=0.006)$. The orientation to place, and attention and calculation scores were also significantly and positively 
Table 1 Demographic characteristics: (A) Sex and education level, and (B) Mean age and MMSE scores with standard deviation (SD)

\begin{tabular}{|c|c|c|}
\hline \multicolumn{3}{|l|}{ A } \\
\hline N (\%) & & $20(100)$ \\
\hline \multicolumn{3}{|l|}{ Sex } \\
\hline Male & & $6(30)$ \\
\hline Female & & $14(70)$ \\
\hline \multicolumn{3}{|l|}{ Education level } \\
\hline Illiterate & & $7(35)$ \\
\hline Literate & & $13(65)$ \\
\hline \multicolumn{3}{|l|}{$\mathrm{B}$} \\
\hline & Mean & $\pm \mathrm{SD}$ \\
\hline Age & 69.85 & 10.03 \\
\hline MMSE overall score (30) & 15.15 & 9.62 \\
\hline Orientation to time (5) & 2.30 & 1.87 \\
\hline Orientation to place (5) & 2.75 & 1.77 \\
\hline Attention and Calculation (17) & 8.55 & 5.72 \\
\hline Recall (3) & 1.40 & 1.04 \\
\hline
\end{tabular}

Table 2 Correlations between MMSE scores and markers recorded from F7

\begin{tabular}{lllllllll}
\hline F7 & $\begin{array}{l}\text { Delta } \\
\text { Median }\end{array}$ & $\begin{array}{l}\text { Theta } \\
\text { Median }\end{array}$ & $\begin{array}{l}\text { Alpha } \\
\text { Median }\end{array}$ & $\begin{array}{l}\text { Theta/Alpha } \\
\text { Power ratio }\end{array}$ & $\begin{array}{l}\text { Delta } \\
\text { Relative power }\end{array}$ & $\begin{array}{l}\text { Theta } \\
\text { Relative power }\end{array}$ & $\begin{array}{l}\text { Alpha } \\
\text { Relative power }\end{array}$ & $\begin{array}{l}\text { Beta } \\
\text { Relative power }\end{array}$ \\
\hline MMSE overall score & -0.519 & -0.581 & -0.256 & -0.674 & -0.512 & -0.627 & 0.744 & 0.655 \\
& 2.647 & 1.018 & 36.112 & 0.314 & 2.920 & 0.432 & $\mathbf{0 . 0 2 4 ^ { * }}$ & 0.243 \\
Orientation to time & -0.509 & -0.604 & -0.453 & -0.543 & -0.371 & -0.640 & 0.523 & 0.704 \\
& 3.062 & 0.666 & 6.317 & 3.379 & 15.030 & 0.332 & 2.511 & 0.0736 \\
Orientation to place & -0.381 & -0.474 & -0.216 & -0.538 & -0.328 & -0.630 & 0.586 & 0.582 \\
Attention and calculation & 13.699 & 4.882 & 50.315 & 4.026 & 22.123 & 0.410 & 0.932 & 1.000 \\
Recall & -0.505 & -0.541 & -0.188 & -0.677 & -0.550 & -0.559 & 0.781 & 0.592 \\
& 3.261 & 1.930 & 59.788 & 0.295 & 1.670 & 1.446 & $\mathbf{0 . 0 0 7 *}$ & 0.836 \\
& -0.474 & -0.510 & -0.243 & -0.629 & -0.495 & -0.510 & 0.660 & 0.551 \\
\end{tabular}

Bold number means positive correlation. First line of each cell represents the Pearson correlation coefficient, and second line represents corrected $p$-value by multiplying by 280

Table 3 Correlations between MMSE scores and markers recorded from F3

\begin{tabular}{|c|c|c|c|c|c|c|c|c|}
\hline F3 & $\begin{array}{l}\text { Delta } \\
\text { Median }\end{array}$ & $\begin{array}{l}\text { Theta } \\
\text { Median }\end{array}$ & $\begin{array}{l}\text { Alpha } \\
\text { Median }\end{array}$ & $\begin{array}{l}\text { Theta/Alpha } \\
\text { Power ratio }\end{array}$ & $\begin{array}{l}\text { Delta } \\
\text { Relative power }\end{array}$ & $\begin{array}{l}\text { Theta } \\
\text { Relative power }\end{array}$ & $\begin{array}{l}\text { Alpha } \\
\text { Relative power }\end{array}$ & $\begin{array}{l}\text { Beta } \\
\text { Relative power }\end{array}$ \\
\hline MMSE overall score & $\begin{array}{l}-0.599 \\
0.740\end{array}$ & $\begin{array}{l}-0.618 \\
0.516\end{array}$ & $\begin{array}{l}-0.328 \\
22.165\end{array}$ & $\begin{array}{l}-0.599 \\
1.476\end{array}$ & $\begin{array}{l}-0.445 \\
6.907\end{array}$ & $\begin{array}{l}-0.604 \\
0.674\end{array}$ & $\begin{array}{l}0.435 \\
7.747\end{array}$ & $\begin{array}{l}0.786 \\
\mathbf{0 . 0 0 6 *}\end{array}$ \\
\hline Orientation to time & $\begin{array}{l}-0.642 \\
0.315\end{array}$ & $\begin{array}{l}-0.667 \\
0.185\end{array}$ & $\begin{array}{l}-0.528 \\
2.342\end{array}$ & $\begin{array}{l}-0.415 \\
19.192\end{array}$ & $\begin{array}{l}-0.330 \\
21.822\end{array}$ & $\begin{array}{l}-0.531 \\
2.231\end{array}$ & $\begin{array}{l}0.214 \\
51.040\end{array}$ & $\begin{array}{l}0.766 \\
\mathbf{0 . 0 1 1 *}\end{array}$ \\
\hline Orientation to place & $\begin{array}{l}-0.624 \\
0.455\end{array}$ & $\begin{array}{l}-0.559 \\
1.462\end{array}$ & $\begin{array}{l}-0.313 \\
24.971\end{array}$ & $\begin{array}{l}-0.471 \\
10.160\end{array}$ & $\begin{array}{l}-0.468 \\
5.256\end{array}$ & $\begin{array}{l}-0.486 \\
4.187\end{array}$ & $\begin{array}{l}0.324 \\
22.863\end{array}$ & $\begin{array}{l}0.731 \\
\mathbf{0 . 0 3 5 *}\end{array}$ \\
\hline Attention and calculation & $\begin{array}{l}-0.520 \\
2.624\end{array}$ & $\begin{array}{l}-0.553 \\
1.597\end{array}$ & $\begin{array}{l}-0.232 \\
45.557\end{array}$ & $\begin{array}{l}-0.623 \\
0.941\end{array}$ & $\begin{array}{l}-0.437 \\
7.520\end{array}$ & $\begin{array}{l}-0.590 \\
0.865\end{array}$ & $\begin{array}{l}0.495 \\
3.685\end{array}$ & $\begin{array}{l}0.722 \\
\mathbf{0 . 0 4 5 *}\end{array}$ \\
\hline Recall & $\begin{array}{l}-0.467 \\
5.306\end{array}$ & $\begin{array}{l}-0.532 \\
2.210\end{array}$ & $\begin{array}{l}-0.279 \\
32.779\end{array}$ & $\begin{array}{l}-0.574 \\
2.273\end{array}$ & $\begin{array}{l}-0.326 \\
22.490\end{array}$ & $\begin{array}{l}-0.565 \\
1.312\end{array}$ & $\begin{array}{l}0.366 \\
15.697\end{array}$ & $\begin{array}{l}0.685 \\
0.121\end{array}$ \\
\hline
\end{tabular}

Bold number means positive correlation. First line of each cell represents the Pearson correlation coefficient, and second line represents corrected $p$-value by multiplying by 280 
correlated with beta relative power ratio with $p$-values equal to 0.015 , and 0.027 , respectively. Any other significance has not been found for correlations between the MMSE scores and markers recorded from Fz (For details, see Table 4).

\section{Fp1, Fp2, F4, and F8 recordings}

Although we have not found any correlations for Fp1, Fp2, F4, and F8 electrodes, detailed results for these electrodes are presented in Table 5. It includes results of studies on alpha, and beta relative powers -i.e. the markers that showed correlations in studies on other electrodes.

\section{Discussion}

Our results indicate that there are correlations between frontal EEG markers and MMSE sub-scores of patients with $\mathrm{AD}$. The results show that among 8 possible markers, the correlations are found only for alpha and beta relative powers. These correlations are consistent with results of Garn et al. study that examined the associations between relative powers and MMSE scores. They found that increasing resting state alpha, delta, and beta relative powers are significantly explainable by increasing MMSE scores [15]. In this study, we found that alpha and beta relative powers are positively correlated with MMSE scores that replicates a part of what Garn et al. found. Cecchetti et al. conducted a study using functional MRI data, laboratory results of cerebrospinal fluid, to evaluate resting state EEG biomarker in diagnosis of $\mathrm{AD}$. Although, they found that theta frequency is earliest and the most sensitive EEG biomarker of AD, they also suggested that alpha band is also a potential biomarker for neurodegeneration [33].

Our results show no strong correlations between resting-state EEG markers and MMSE scores in Fp1 and $\mathrm{Fp} 2$, as Choi et al. found that there is a moderate correlation [16]. While Doan et al. based on correlations they have found for prefrontal recordings (i.e., $\mathrm{Fp} 1$, and $\mathrm{Fp} 2$ ),

Table 4 Correlations between MMSE scores and markers recorded from Fz

\begin{tabular}{llllllll}
\hline Fz & $\begin{array}{l}\text { Delta } \\
\text { Median }\end{array}$ & $\begin{array}{l}\text { Theta } \\
\text { Median }\end{array}$ & $\begin{array}{l}\text { Alpha } \\
\text { Median }\end{array}$ & $\begin{array}{l}\text { Theta/Alpha } \\
\text { power ratio }\end{array}$ & $\begin{array}{l}\text { Delta } \\
\text { Relative power }\end{array}$ & $\begin{array}{l}\text { Theta } \\
\text { Relative power }\end{array}$ & $\begin{array}{l}\text { Alpha } \\
\text { Relative power }\end{array}$ \\
& & -0.439 & -0.568 & -0.199 & -0.599 & -0.357 & -0.614 \\
Relative power
\end{tabular}

Bold number means positive correlation. First line of each cell represents the Pearson correlation coefficient, and second line represents corrected $p$-value by multiplying by 280

Table 5 Results of study on correlations between MMSE scores and alpha, and beta relative powers recorded from Fp1, Fp2, F4, and F8 electrodes

\begin{tabular}{|c|c|c|c|c|c|c|c|c|}
\hline \multirow{2}{*}{$\begin{array}{l}\text { Electrode } \\
\text { Marker }\end{array}$} & \multicolumn{2}{|l|}{ Fp1 } & \multicolumn{2}{|l|}{ Fp2 } & \multicolumn{2}{|l|}{ F4 } & \multicolumn{2}{|l|}{ F8 } \\
\hline & $\begin{array}{l}\text { Alpha } \\
\text { Relative } \\
\text { power }\end{array}$ & $\begin{array}{l}\text { Beta } \\
\text { Relative } \\
\text { power }\end{array}$ & $\begin{array}{l}\text { Alpha } \\
\text { Relative } \\
\text { power }\end{array}$ & $\begin{array}{l}\text { Beta } \\
\text { Relative } \\
\text { power }\end{array}$ & $\begin{array}{l}\text { Alpha } \\
\text { Relative } \\
\text { power }\end{array}$ & $\begin{array}{l}\text { Beta } \\
\text { Relative } \\
\text { power }\end{array}$ & $\begin{array}{l}\text { Alpha } \\
\text { Relative } \\
\text { power }\end{array}$ & $\begin{array}{l}\text { Beta } \\
\text { Relative power }\end{array}$ \\
\hline $\begin{array}{l}\text { MMSE overall } \\
\text { score }\end{array}$ & $\begin{array}{l}0.412 \\
9.947\end{array}$ & $\begin{array}{l}0.475 \\
4.812\end{array}$ & $\begin{array}{l}0.420 \\
9.083\end{array}$ & $\begin{array}{l}0.400 \\
11.262\end{array}$ & $\begin{array}{l}0.446 \\
6.788\end{array}$ & $\begin{array}{l}0.477 \\
4.675\end{array}$ & $\begin{array}{l}0.699 \\
0.084\end{array}$ & $\begin{array}{l}0.457 \\
6.018\end{array}$ \\
\hline $\begin{array}{l}\text { Orientation to } \\
\text { time }\end{array}$ & $\begin{array}{l}0.214 \\
51.239\end{array}$ & $\begin{array}{l}0.570 \\
1.219\end{array}$ & $\begin{array}{l}0.224 \\
47.974\end{array}$ & $\begin{array}{l}0.499 \\
3.500\end{array}$ & $\begin{array}{l}0.191 \\
58.664\end{array}$ & $\begin{array}{l}0.595 \\
0.797\end{array}$ & $\begin{array}{l}0.528 \\
2.347\end{array}$ & $\begin{array}{l}0.547 \\
1.765\end{array}$ \\
\hline $\begin{array}{l}\text { Orientation to } \\
\text { place }\end{array}$ & $\begin{array}{l}0.340 \\
20.023\end{array}$ & $\begin{array}{l}0.445 \\
6.938\end{array}$ & $\begin{array}{l}0.340 \\
19.981\end{array}$ & $\begin{array}{l}0.365 \\
15.912\end{array}$ & $\begin{array}{l}0.357 \\
17.086\end{array}$ & $\begin{array}{l}0.454 \\
6.211\end{array}$ & $\begin{array}{l}0.586 \\
0.925\end{array}$ & $\begin{array}{l}0.432 \\
7.961\end{array}$ \\
\hline $\begin{array}{l}\text { Attention and } \\
\text { Calculation }\end{array}$ & $\begin{array}{l}0.460 \\
5.762\end{array}$ & $\begin{array}{l}0.402 \\
11.067\end{array}$ & $\begin{array}{l}0.470 \\
5.127\end{array}$ & $\begin{array}{l}0.342 \\
19.655\end{array}$ & $\begin{array}{l}0.504 \\
3.286\end{array}$ & $\begin{array}{l}0.409 \\
10.218\end{array}$ & $\begin{array}{l}0.711 \\
0.061\end{array}$ & $\begin{array}{l}0.392 \\
12.259\end{array}$ \\
\hline Recall & $\begin{array}{l}0.323 \\
23.024\end{array}$ & $\begin{array}{l}0.407 \\
10.453\end{array}$ & $\begin{array}{l}0.330 \\
21.683\end{array}$ & $\begin{array}{l}0.309 \\
25.921\end{array}$ & $\begin{array}{l}0.411 \\
10.083\end{array}$ & $\begin{array}{l}0.326 \\
22.414\end{array}$ & $\begin{array}{l}0.615 \\
0.543\end{array}$ & $\begin{array}{l}0.356 \\
17.288\end{array}$ \\
\hline
\end{tabular}

First line of each cell represents the Pearson correlation coefficient, and second line represents corrected $p$-value by multiplying by 280 . No significant correlation has been found 
concluded that prefrontal EEG biomarkers can be predicting dementia [17], we suggest that it would be helpful to consider correlations between MMSE scores and EEG markers recorded from F3, F7, and Fz (See Tables 2, 3, 4). It seems that if we want to develop predicting models for $\mathrm{AD}$, using data recorded from other frontal electrodes, especially what we have introduced should be considered.

The main benefit that can be gotten from our results is to use them to develop models for diagnosis of AD. These models simply get data from electrode recordings and give a prediction of the severity of the disease. Many other outputs can be conceived with various purposes. For example, we can change the output to the level of response to a specific medication, or change it to the type of dementia, etc. A good example of this modeling is what Choi et al. introduced for predictive model to early diagnosis of dementia, using EEG signals [16]. However, our results are not the same with what Choi et al. introduced. It may be used for assessments of cognitive abilities in more severe cases, and for modeling the prognosis of disease.

In this study, we generally examined correlations in AD patients. We propose three other areas that are very close to the subject of this study. First, it is conceivable to design studies on correlations of MMSE scores and EEG markers to compare AD with non-AD patients. These studies should be performed to find differences between types of dementia. Those studies would help to develop precise models to differentiate between $A D$ from other types of dementia. Second, another subject that can be pursued by further studies is evaluating effects of sociodemographic characteristics on the correlations between MMSE scores and EEG markers. Finally, to study relationships of the correlations with prognoses of patients, we propose designing cohort studies, exactly with the same method. The recorded data in cohort study would provide evidence for predicting models for patients' prognoses.

\section{Limitations}

Our study had at least two limitations: (1) limited number of eligible patients enrolled in the study, (2) absence of control groups-e.g., healthy group or non-AD patients with other types of dementia. Because this study was not supported by any grants, it was difficult for us to address these limitations.

\section{Conclusions}

Following recent studies to develop diagnostic tools for AD based on qEEG, we suggest that it can be effective if it is indicated that EEG biomarkers recorded from which electrodes show strongest correlations with AD. Reliable strong correlations guide us to develop predicting models more confident. Therefore, we hope that further studies on this topic indicate this issue.

\section{Abbreviations}

AD: Alzheimer's Disease; MMSE: Mini Mental State Examination; EEG: Electroencephalography; SD: Standard deviation.

\section{Acknowledgements \\ Not applicable.}

\section{Authors' contributions}

All authors have contributed in idea generation, data acquisition, data analysis, writing the manuscript, and editing the manuscript. All authors read and approved the final manuscript.

\section{Funding}

This article is not supported by any funding.

Availability of data and materials

All data are storage by the Asab Pajoohan Farda Research Company.

\section{Declarations}

Ethical approval and consent to participate

Ethical approval was taken from Research Ethical Committee of Institute for Cognitive and Brain Sciences, Shahid Beheshti University. Informed consents for entering to the study were taken by caregivers of patients.

\section{Consent for publication}

All the authors have consented for the publication.

\section{Competing interests}

There is no competing interests in this research.

\section{Author details}

${ }^{1}$ Asab Pajouhan Farda Research Company, Tehran, Iran. ${ }^{2}$ Cognitive Rehabilitation Clinic, Institute for Cognitive and Brain Sciences, Shahid Beheshti University, Tehran, Iran. ${ }^{3}$ Student Research Committee, Faculty of Medicine, Shahid Beheshti University of Medical Sciences, Tehran, Iran. ${ }^{4}$ Faculty of Veterinary Medicine, Urmia University, Urmia, Iran.

Received: 21 December 2021 Accepted: 19 February 2022

Published online: 07 March 2022

\section{References}

1. Haines JL. Alzheimer Disease: perspectives from epidemiology and genetics. J Law Med Ethics. 2018:46(3):694-8.

2. As A. 2018 Alzheimer's disease facts and figures. Alzheimers Dement. 2018;14(3):367-429.

3. McKhann G, Drachman D, Folstein M, Katzman R, Price D, Stadlan EM. Clinical diagnosis of Alzheimer's disease: report of the NINCDS-ADRDA Work Group under the auspices of Department of Health and Human Services Task Force on Alzheimer's Disease. Neurology. 1984;34(7):939-44.

4. Galea M, Woodward M. Mini-mental state examination (MMSE). Aust J Physiother. 2005;51(3):198.

5. Dubois B, Feldman HH, Jacova C, Dekosky ST, Barberger-Gateau P, Cummings J, et al. Research criteria for the diagnosis of Alzheimer's disease: revising the NINCDS-ADRDA criteria. Lancet Neurol. 2007:6(8):734-46.

6. Jelic V, Kowalski J. Evidence-based evaluation of diagnostic accuracy of resting EEG in dementia and mild cognitive impairment. Clin EEG Neurosci. 2009;40(2):129-42.

7. Koberda JL. QEEG as a useful tool for the evaluation of early cognitive changes in dementia and traumatic brain injury. Clin EEG Neurosci. 2021;52(2):119-25.

8. Arns M, Gordon E. Quantitative EEG (QEEG) in psychiatry: diagnostic or prognostic use? Clin Neurophysiol. 2014;125(8):1504-6. 
9. Jelic V, Johansson SE, Almkvist O, Shigeta M, Julin P, Nordberg A, et al. Quantitative electroencephalography in mild cognitive impairment: longitudinal changes and possible prediction of Alzheimer's disease. Neurobiol Aging. 2000;21(4):533-40.

10. Prinz PN, Vitiello MV. Dominant occipital (alpha) rhythm frequency in early stage Alzheimer's disease and depression. Electroencephalogr Clin Neurophysiol. 1989;73(5):427-32.

11. Prichep LS, John ER, Ferris SH, Reisberg B, Almas M, Alper K, et al. Quantitative EEG correlates of cognitive deterioration in the elderly. Neurobiol Aging. 1994;15(1):85-90

12. Chiaramonti R, Muscas GC, Paganini M, Müller TJ, Fallgatter AJ, Versari A, et al. Correlations of topographical EEG features with clinical severity in mild and moderate dementia of Alzheimer type. Neuropsychobiology. 1997;36(3):153-8.

13. Moretti DV, Babiloni C, Binetti G, Cassetta E, Dal Forno G, Ferreric F, et al. Individual analysis of EEG frequency and band power in mild Alzheimer's disease. Clin Neurophysiol. 2004;115(2):299-308.

14. Adamis D, Sahu S, Treloar A. The utility of EEG in dementia: a clinical perspective. Int J Geriatr Psychiatry. 2005;20(11):1038-45.

15. Garn H, Waser M, Deistler M, Schmidt R, Dal-Bianco P, Ransmayr G, et al. Quantitative EEG in Alzheimer's disease: cognitive state, resting state and association with disease severity. Int J Psychophysiol. 2014;93(3):390-7.

16. Choi J, Ku B, You YG, Jo M, Kwon M, Choi Y, et al. Resting-state prefrontal EEG biomarkers in correlation with MMSE scores in elderly individuals. Sci Rep. 2019;9(1):10468.

17. Doan DNT, Ku B, Choi J, Oh M, Kim K, Cha W, et al. Predicting dementia with prefrontal electroencephalography and event-related potential. Front Aging Neurosci. 2021;13:659817.

18. Guerrero-Berroa E, Luo X, Schmeidler J, Rapp MA, Dahlman K, Grossman $H T$, et al. The MMSE orientation for time domain is a strong predictor of subsequent cognitive decline in the elderly. Int I Geriatr Psychiatry. 2009;24(12):1429-37.

19. Martin RC, Annis SM, Darling LZ, Wadley V, Harrell L, Marson DC. Loss of calculation abilities in patients with mild and moderate Alzheimer disease. Arch Neurol. 2003;60(11):1585-9.

20. Halpern C, McMillan C, Moore P, Dennis K, Grossman M. Calculation impairment in neurodegenerative diseases. J Neurol Sci. 2003;208(1-2):31-8.

21. Laakso MP, Hallikainen M, Hanninen T, Partanen $K$, Soininen H. Diagnosis of Alzheimer's disease: MRI of the hippocampus vs delayed recall. Neuropsychologia. 2000;38(5):579-84.

22. Tsoi KK, Chan JY, Hirai HW, Wong A, Mok VC, Lam LC, et al. Recall tests are effective to detect mild cognitive impairment: a systematic review and meta-analysis of 108 diagnostic studies. J Am Med Directors Assoc. 2017;18(9):807.e17-e19.

23. Flinker A, Korzeniewska A, Shestyuk AY, Franaszczuk PJ, Dronkers NF, Knight RT, et al. Redefining the role of Broca's area in speech. Proc Nat Acad Sci U S A. 2015;112(9):2871-5.

24. Neulinger K, Oram J, Tinson H, O'Gorman J, Shum DH. Prospective memory and frontal lobe function. Neuropsychol Dev Cogn B Aging Neuropsychol Cogn. 2016;23(2):171-83.

25. McKhann GM, Knopman DS, Chertkow H, Hyman BT, Jack CR Jr, Kawas $\mathrm{CH}$, et al. The diagnosis of dementia due to Alzheimer's disease: recommendations from the National Institute on Aging-Alzheimer's Association workgroups on diagnostic guidelines for Alzheimer's disease. Alzheimers Dement. 2011;7(3):263-9.

26. Seyedian M, Falah M, Nourouzian M, Nejat S, Delavar A, Ghasemzadeh H. Validity of the Farsi version of mini-mental state examination. 2008.

27. Pop-Jordanova N. ADHD as a specific cause for learning disability. S M, editor. London: IntechOpen; 2020.

28. Jung TP, Makeig S, Humphries C, Lee TW, McKeown MJ, Iragui V, et al. Removing electroencephalographic artifacts by blind source separation. Psychophysiology. 2000;37(2):163-78.

29. Nolan $H$, Whelan $R$, Reilly RB. FASTER: fully automated statistical thresholding for EEG artifact rejection. J Neurosci Methods. 2010;192(1):152-62.

30. Jelic V, Shigeta M, Julin P, Almkvist O, Winblad B, Wahlund LO. Quantitative electroencephalography power and coherence in Alzheimer's disease and mild cognitive impairment. Dementia. 1996;7(6):314-23.

31. Dauwels J, Srinivasan K, Ramasubba Reddy M, Musha T, Vialatte FB, Latchoumane C, et al. Slowing and loss of complexity in Alzheimer's EEG: two sides of the same coin? Int J Alzheimers Dis. 2011;2011:539621.
32. Bian Z, Li Q, Wang L, Lu C, Yin S, Li X. Relative power and coherence of EEG series are related to amnestic mild cognitive impairment in diabetes. Front Aging Neurosci. 2014;6:11.

33. Cecchetti G, Agosta F, Basaia S, Cividini C, Cursi M, Santangelo R, et al. Resting-state electroencephalographic biomarkers of Alzheimer's disease. Neuroimage Clin. 2021;31:102711.

\section{Publisher's Note}

Springer Nature remains neutral with regard to jurisdictional claims in published maps and institutional affiliations.

\section{Submit your manuscript to a SpringerOpen ${ }^{\circ}$ journal and benefit from:}

- Convenient online submission

- Rigorous peer review

- Open access: articles freely available online

- High visibility within the field

- Retaining the copyright to your article

Submit your next manuscript at $\boldsymbol{\nabla}$ springeropen.com 